\title{
Nanosized rods agglomerates as a new approach for formulation of a dry powder inhaler
}

\author{
This article was published in the following Dove Press journal: \\ International Journal of Nanomedicine \\ 3 February 2011 \\ Number of times this article has been viewed
}

\author{
HF Salem' \\ ME Abdelrahim ${ }^{2}$ \\ K Abo $\mathrm{Eid}^{3}$ \\ MA Sharaf ${ }^{3,4}$ \\ 'Department of Pharmaceutics, \\ ${ }^{2}$ Department of Clinical Pharmacy, \\ Faculty of Pharmacy, The University \\ of Beni Suef, Beni Suef; ${ }^{3}$ Department \\ of Chemistry, Helwan University, Ain \\ Helwan, Helwan, Egypt; ${ }^{4}$ Department \\ of Chemistry, The American University \\ in Cairo, New Cairo, Helwan I I835, \\ Egypt
}

Background: Nanosized dry powder inhalers provide higher stability for poorly water-soluble drugs as compared with liquid formulations. However, the respirable particles must have a diameter of $1-5 \mu \mathrm{m}$ in order to deposit in the lungs. Controlled agglomeration of the nanoparticles increases their geometric particle size so they can deposit easily in the lungs. In the lungs, they fall apart to reform nanoparticles, thus enhancing the dissolution rate of the drugs. Theophylline is a bronchodilator with poor solubility in water.

Methods: Nanosized theophylline colloids were formed using an amphiphilic surfactant and destabilized using dilute sodium chloride solutions to form the agglomerates.

Results: The theophylline nanoparticles thus obtained had an average particle size of $290 \mathrm{~nm}$ and a zeta potential of $-39.5 \mathrm{mV}$, whereas the agglomerates were $2.47 \mu \mathrm{m}$ in size with a zeta potential of $-28.9 \mathrm{mV}$. The release profile was found to follow first-order kinetics $\left(\mathrm{r}^{2}>0.96\right)$. The aerodynamic characteristics of the agglomerated nanoparticles were determined using a cascade impactor. The behavior of the agglomerate was significantly better than unprocessed raw theophylline powder. In addition, the nanoparticles and agglomerates resulted in a significant improvement in the dissolution of theophylline.

Conclusion: The results obtained lend support to the hypothesis that controlled agglomeration strategies provide an efficient approach for the delivery of poorly water-soluble drugs into the lungs.

Keywords: theophylline, nanoparticles, agglomerates, dry powder inhaler

\section{Introduction}

Drug delivery to the lungs using dry powder inhalers has attracted scientific and biomedical attention in recent years. ${ }^{1-4}$ It has many advantages over other sites of administration because it has a fast onset of action, high bioavailability, avoidance of the first-pass effect, local action for pulmonary diseases, and convenience to patients when administered., Theophylline is a bronchodilator and is efficient in the treatment of asthma and stable chronic obstructive pulmonary disease ${ }^{6,7}$ However, there is a tendency to reduce its use due to its complicated pharmacokinetic characteristics. ${ }^{8-15}$ It has a very narrow therapeutic window so that the range between the therapeutic dose and the toxic dose is quite narrow. ${ }^{11,14,16,17}$ Theophylline is a poorly water-soluble drug. ${ }^{18,19}$ Increasing the solubility of theophylline may reduce the border between the effective concentration and the toxic concentration. ${ }^{20}$ Theophylline is used in conjunction with small doses of beta agonists in the treatment of asthma; ${ }^{21}$ however, this combination may cause side effects, including hypokalemia. ${ }^{15,22,23}$ Particular care is mandatory when introducing or withdrawing drugs that interact with theophylline. A plasma theophylline concentration of $10-20 \mathrm{mg} / \mathrm{L}$ is
Correspondence: MA Sharaf Department of Chemistry, The American University in Cairo, New Cairo, Helwan II835, Egypt Tel 0020121076312

Fax 00202275I44II

Email sharafma@aucegypt.edu 
required to achieve a therapeutic effect. Adverse effects can occur within a range of $10-20 \mathrm{mg} / \mathrm{L} .{ }^{14}$ The severity of side effects increases at concentrations above $20 \mathrm{mg} / \mathrm{L} .{ }^{16}$ Many side effects can occur due to a theophylline overdose, such as tachycardia, palpitations, central nervous system stimulation, arrhythmias and convulsions; it can also induce life-threatening seizures in humans, especially in infants. ${ }^{10,24,25}$ Therefore, current oral doses of theophylline need to be controlled or reduced to minimize the danger of toxicity.

The administration of bronchodilators in dry powder aerosol form is one of the proposed strategies that can be adopted to reduce doses and, consequently, to reduce the side effects. Because inhaled powders work locally in the lung as a common site of action, lower doses are needed to achieve the same therapeutic effect as the oral doses.

The aerodynamic diameter has been used for several decades to measure the intrinsic tendency of aerosol particles to deposit in the lungs, due to their shape, density, and geometric size. In several studies, the most favorable particle size of aerosol particles was determined for several different drugs when given to patients. The optimal size of the particles for deposition in the lungs was found to be in the $1-5 \mu \mathrm{m}$ range. ${ }^{26,27}$ For porous particles, which have a low density, their aerodynamic diameter can be smaller than their corresponding geometric diameter, ${ }^{28}$ therefore they can be used to improve drug deposition in peripheral regions.

There has been huge success in processing dry powder inhalers using a range of drug substances, including nifedipine, ciprofloxacin, tacrolimus, and budesonide. ${ }^{29-33}$ To the best of our knowledge, this is the only study demonstrating the use of agglomerated nanoparticles of theophylline as a dry powder for inhalers. Therefore, the aim of this study was to formulate self-assembled, theophylline nanoparticle agglomerates as a dry powder for inhalers. Nanoparticle were employed and manipulated to form self-assembled spherical rose-shaped agglomerates via destabilization of negatively charged nanosized theophylline powders. Stearic acid, as an amphiphilic moiety, was used as a stabilizer for the nanosuspension and the charges provided by stearic acid facilitated the agglomeration of the nanoparticles with addition of electrolytes. The nanoparticle agglomerates produced were found to have excellent inhalation properties and improved physicochemical properties compared with the unprocessed drug.

\section{Materials and methods Materials}

Theophylline, stearic acid, and sodium chloride were provided by El Gomhoria CO (Arab Republic of Egypt).
Ethanol (95\% v/v) and dimethylformamide were purchased from Fisher Scientific (Egypt) and used without manipulation. Phosphate-buffered saline was purchased from Sigma Chemicals (Egypt). Eighteen ohm water was obtained from a Millipore unit present at Helwan University (Cairo, Egypt).

\section{Processing of nanotheophylline}

Nanoparticles were prepared according to the procedure of Plumely et al, with some modifications. ${ }^{29}$ Theophylline $40 \mathrm{mg}$ and stearic acid either $5 \%$ or $10 \% \mathrm{w} / \mathrm{w}$ were dissolved in dimethylformamide $12 \mathrm{~mL}$ and ethanol $1 \mathrm{~mL}$ and then allowed to mix overnight. This solution was added to water $60 \mathrm{~mL}$ via a microsyringe under probe sonication (Bandolin Electronic, model GM2200, GmbH) at low amplitude and 20 second cycles for a total time of 120 seconds. The resulting nanoparticles were either stored at $4^{\circ} \mathrm{C}$ or were frozen at $-20^{\circ} \mathrm{C}$, then lyophilized using a freeze dryer (EF03, Edwards High Vacuum Ltd, UK).

\section{Agglomerations of the nanoparticles}

Nanoparticle suspensions were agglomerated by ionic interaction of a diluted solution of strong electrolytes. Different increments of diluted $\mathrm{NaCl}$ salt solutions that ranged from $0.5 \mathrm{~mL}$ to $1.0 \mathrm{~mL}\left(1 \times 10^{-3} \mathrm{M}\right)$ were added to the nanosuspension solutions $(73 \mathrm{~mL})$. The nanosuspensions were then mixed vigorously at $2000 \mathrm{rpm}$ for 10 minutes. The samples were left at room temperature for 24 hours and then lyophilized (EF03, Edwards High Vacuum Ltd). The samples were stored in glass vessels in the refrigerator until further use. The effect of the concentrated electrolytes on agglomeration of the nanoparticles was investigated using $\mathrm{NaCl}$ salt solutions ranging from $0.5-1.0 \mathrm{~mL}(0.1 \mathrm{M})$.

\section{Physicochemical characterization of the nanoparticles and the agglomerates} Solid state characterization

The tapped and untapped densities (fluff) were evaluated using a small graduated tube with a defined volume size into which known weights of the powders were added. Dividing the mass of the powder by the volume is known as bulk density. Tapping this tube up and down against a protected bench 100 times corresponded with the tapped volume. Dividing the weight of the new volume gave the tapped density. The Hausner ratio is calculated by dividing the tapped density/bulk density. Carr's index is calculated using Equation 1:

$$
\mathrm{C}_{\mathrm{i}}=(\text { tapped d-bulk } \mathrm{d}) / \text { tapped } \mathrm{d} \times 100 \%
$$


The angle of repose was calculated by forming a pile that was carefully built up by allowing the powders to fall through a funnel until the tip of the funnel was $2 \mathrm{~cm}$ apart. The angle of repose was calculated using the ratio between the height and the radius of the pile formed.

\section{Particle size and zeta potential analysis}

The mean particle size diameter and polydispersity index were measured in solution directly after synthesis using photon correlation spectroscopy (Mastersizer, Malvern, UK). Theophylline nanosuspensions and agglomerates $(2 \mathrm{~mL})$ were added to the quartz cell of the photon correlation spectroscope. Measurements were taken at $90^{\circ}$ opposite the incident light source. A fixed volume of the samples were used to measure the zeta potential of the nanoparticles. The $\mathrm{pH}$ was adjusted to different $\mathrm{pH}$ values. Zeta potential values were measured by a Zetasizer 2000 (Malvern) using $\mathrm{KC} 1(1 \mathrm{mM})$ as the running buffer.

\section{Calculation of the recovery}

The agglomerates were evaluated both as a suspension and as a dry powder. After controlled agglomeration was recognized, a small volume ( $2 \mathrm{~mL}$ ) of each sample was examined using photon correlation spectroscopy (Malvern Mastersizer, UK). After lyophilization, the recovery was calculated using Equation (2):

$$
\text { Recovery }=\mathrm{W}_{\mathrm{p}} / \mathrm{W}_{\mathrm{I}} \times 100
$$

where the weight of the powder produced $\left(\mathrm{W}_{\mathrm{P}}\right)$ is the weight of the solid weight after lyophilization, and the weight of added powder $\left(\mathrm{W}_{\mathrm{I}}\right)$ includes the weights of both the added theophylline and stearic acid.

\section{Scanning electron microscopy}

Samples of the theophylline powder, nanosuspension, and agglomerates as dry powders were mounted on copper stubs and coated with gold using the coating sputter (S150A Edwards, UK). The sample was examined under a JXA-840A electron probe microanalyzer (Jeol, Japan).

\section{Differential scanning calorimetry}

Theophylline powder, stearic acid, theophylline nanoparticles, and theophylline agglomerates $(4 \mathrm{mg})$ were sealed in the flat-bottomed aluminum pan of the differential scanning calorimeter (Shimadzu DSC-50, Japan). A standard empty pan was inserted along with each pan to account for the heating of pure aluminum. The sample and the blank were continuously purged with nitrogen gas at a flow rate of $25 \mathrm{~mL} / \mathrm{min}$. Data collection was carried out at a temperature range of $20-300^{\circ} \mathrm{C}$, and the heating rate was $10^{\circ} \mathrm{C} / \mathrm{min}$. The melting and transition point measurements were performed using the software provided with the device.

\section{Dissolution study}

Dissolution was carried out using dry samples of nanoparticles, agglomerated nanoparticles, and theophylline powder (4 mg) each, suspended in phosphate-buffered saline (1 mL, pH 7.4) and released into the dissolution medium through a dialysis bag with a molecular weight cut off of $12,000 \mathrm{Da}$. The sink conditions were achieved using 10 times the volume of saturation solubility. The samples of nanoparticles, nanoparticle agglomerates, and theophylline powder were withdrawn at specified intervals over eight hours. The samples were measured spectrophotometrically at $\lambda_{274}$ (Jasco V530, Japan).

\section{Aerodynamic characterization Total emitted dose}

Amounts of pure powder, nanoparticles and agglomerate, equivalent to theophylline $80 \mathrm{mg}$, were separately placed into capsules suitable for the dry powder inhaler in order to test their aerodynamic characteristics (Aerolizer, Novartis Pharma, Egypt). The dose emitted from the Aerolizer was measured using a dry powder inhaler sampling apparatus with a critical flow controller (model TPK, Copley Scientific Ltd, UK). The final filter was a $47 \mathrm{~mm} \mathrm{~A} / \mathrm{E}$ fiberglass filter disc (Pall Corporation, Washington, NY). The inhalation flow through the mouthpiece of the Aerolizer was set at $60 \mathrm{~L} / \mathrm{min}$ with a flow duration of four seconds to allow an inhaled volume of $4 \mathrm{~L}$ of air to be drawn through the inhaler. ${ }^{34-36}$ The dose emitted from the Aerolizer was measured by collecting one individual dose each time. The emitted dose test was repeated 10 times for each formula $(n=10)$.

Following dose emission into the apparatus, the sampling unit was washed and the filter was completely submerged in $10 \%$ methanol and then sonicated for three minutes. The amount of drug was determined by high performance liquid chromatography ${ }^{37}$ using a monolithic column RP-18e $100 \times 4.6 \mathrm{~mm}$ through which a mobile phase of methanol-10 $\mathrm{mM} \mathrm{KH}_{2} \mathrm{PO}_{4}$ $(\mathrm{pH} 4)$ at a ratio of 12.5:87.5\% v/v, was pumped at $1 \mathrm{~mL} / \mathrm{min}$. The ultraviolet detector (RF-551, Shimadzu, Japan) was set at a wavelength of $274 \mathrm{~nm}$. The limit of detection was $0.014 \mu \mathrm{g} /$ $\mathrm{mL}$ and the lower limit of quantification was $0.041 \mu \mathrm{g} / \mathrm{mL}$.

\section{Aerodynamic particle size characterization}

All parts of the Andersen MKII Cascade Impactor (including the preseparator) were washed in methanol and allowed to 
dry. The impactor was assembled with the modification plates for a flow rate of $60 \mathrm{~L} / \mathrm{min}$, hence stages 0 and 7 were replaced by -0 and -1 on the top of the impactor. The collection plates were then sprayed with silicone fluid (Releasil B silicone spray, Dow Corning Limited, Glamorgan, UK) and allowed to dry for at least one hour prior to analysis. The cascade impactor was assembled with $10 \mathrm{~mL}$ of $10 \%$ methanol placed in the preseparator and the final filter was a GF 50 (Copley Scientific Ltd).

The flow rate through the mouthpiece of the Aerolizer was set at $60 \mathrm{~L} / \mathrm{min}$ through the impactor with a flow duration of four seconds (corresponding to $4 \mathrm{~L}$ through the inhaler). The flow was measured using an electronic digital flow meter (MKS Instruments, San Jose, CA) and a critical flow controller model TPK (Copley Scientific Ltd). Parafilm M laboratory film (Pechiney Plastic Packaging, Neenah, WI) was used to seal the apparatus.

The pump (set for the required flow) was switched on for the previously mentioned inhalation time to allow a volume of $4 \mathrm{~L}$ of air, as recommended in the pharmacopeial methods, ${ }^{34-36}$ to be drawn through the inhaler during each determination. Only one dose was discharged into the impactor for each determination. Five separate determinations were made $(n=5)$ for each flow. Each stage of the cascade impactor was rinsed with a specified volume of methanol $10 \%$. The washing procedure was the same as the procedure described for the total dose emission. The amounts deposited on each stage were determined by high-performance liquid chromatography.

\section{Data analysis}

The total dose emission was determined as the total amount of drug ex-mouthpiece. This was reported with respect to the nominal emitted dose. Using the impactor with a flow rate of $60 \mathrm{~L} / \mathrm{min}$, the effective cutoff diameter of each stage was fixed to $60 \mathrm{~L} / \mathrm{min}$ flow. ${ }^{38,39}$ The fine particle dose was the amount of particles that corresponded to a size less than $5 \mu \mathrm{m}$. The fine particle fraction was the fine particle dose expressed as a percentage of the total amount deposited into the throat and stages of the cascade impactor (the dose that exited the mouthpiece). The mass median aerodynamic diameter was obtained from a plot of the logarithm of the percentage less than a stated size on a probability scale against the logarithm of the effective cutoff diameter of the stage, ${ }^{34-36}$ and this was done using Copley Inhaler Testing Data Analysis Software. The mass median aerodynamic diameter was the diameter corresponding to $50 \%$ undersize. The geometric standard deviation was the square root for the size corresponding to
$84.13 \%$ less than the stated size divided by the square root of the size for $15.87 \% .{ }^{34-36}$ The aerodynamic results were compared using a paired $t$-test.

\section{Results and discussion}

The possibility of producing controlled agglomerates from a nanosuspension of poorly water-soluble drugs has been reported previously. ${ }^{29,40-43}$ However, many different techniques can be used to achieve this goal, such as using the nanoparticles, ${ }^{44}$ using the micronized form of poorly water-soluble drugs ${ }^{45,46}$ and even using four-fluid spray driers to prepare microparticles containing water-insoluble drugs. ${ }^{47-49}$ In this study, the theophylline agglomerate was prepared at a respirable particle size (1-5 $\mu \mathrm{m})$ using the solvent antisolvent technique..$^{29,45-50}$ First, the drug was dissolved with stearic acid in an organic solvent and then precipitated as nanoparticles by dropping this solution into an antisolvent. For agglomeration, the addition of monovalent cations is a well known procedure resulting in the agglomeration of phospholipids, solid lipid nanoparticles, and nanosuspensions. ${ }^{42,51,52}$ It was reported that different types of monovalent cations can be chosen in order to control the degree of agglomeration. ${ }^{53}$

The order of the capability of monovalent cations to induce the initial phase of the agglomeration of large phospholipid vesicles was reported to be: $\mathrm{Li}^{+}>\mathrm{Na}^{+}>\mathrm{K}^{+}>$Tris ions. Lithium is a toxic cation. Therefore, $\mathrm{Na}^{+}$was used in this study to induce agglomeration. ${ }^{54}$

Stearic acid was chosen as the stabilizer because it possesses many advantages, including the fact that it works as an amphiphilic surfactant, is cheap, and has no cationic roots. For example, $\mathrm{Mg}$ stearate has $\mathrm{Mg}^{+2}$ as a cationic root, so it can interfere with the agglomeration process. ${ }^{55,56}$ Stearic acid exists in a solid state at room temperature, which is thought to help in the formation of a thin layer surrounding the drug nanodispersion. ${ }^{57}$ The amphiphilic nature of stearic acid makes it perform as a boundary between theophylline nanoparticles and the hydrophilic medium in the lungs. ${ }^{29}$

All of the nanosuspension formulations demonstrated a macroscopic homogenous appearance, which was pale cloudy white in color when examined by eye before lyophilization. After lyophilization, they appeared as a flowing white powder. The agglomerates produced were white fluffy powders completely different in their macroscopic characteristics from either the nanoparticles or the parent theophylline powder.

The amount of stearic acid added significantly affected the size of the nanoparticles produced. The particles with the smallest sizes were those produced with the highest ratio of 
Table I The recovery, particle size, and polydispersity indices of theophylline nanoparticles and theophylline agglomerates

\begin{tabular}{lllll}
\hline Particles & $\begin{array}{l}\text { Stearic acid } \\
\text { (\% w/w) }\end{array}$ & $\begin{array}{l}\text { Recovery } \\
\text { (\%) }\end{array}$ & $\begin{array}{l}\text { Particle size } \\
\text { (nm) }\end{array}$ & PI \\
\hline Nanoparticles & 5 & $47 \pm 07$ & $470 \pm 20$ & $0.65 \pm 0.14$ \\
& 10 & $70 \pm 18$ & $290 \pm 22$ & $0.21 \pm 0.02$ \\
Agglomerates & 5 & $66 \pm 19$ & $880 \pm 180$ & $0.55 \pm 0.11$ \\
& 10 & $90 \pm 03$ & $2470 \pm 120$ & $0.67 \pm 0.16$ \\
\hline
\end{tabular}

Abbreviation: Pl, polydispersity index.

stearic acid (Table 1). The recovery was also improved by increasing the concentration of stearic acid used, which may have happened due to the repulsion occurring between the nanoparticle surfaces and the walls of the glass vessels upon transfer. The ratio between theophylline and stearic acid was presumed to remain the same after lyophilization in each case. Particle size analysis showed the presence of nanoparticles with low polydispersity indices (Table 1). The size distribution was in concurrence with other nanosuspension systems described in the literature. ${ }^{29}$ The photon correlation spectroscopy results were in agreement with the electron micrograph results. Scanning electron microscopy showed the formation of elliptically shaped nanoparticles that started to arrange themselves in rosy clusters once placed on a copper grid for the photographs (Figures 1A and 1B). This phenomenon means that these nanoparticles can be destabilized in the presence of diluted concentrations of any cation. The agglomeration occurred in a dendritic shape (Figures 1C and 1D) which provided a porous structure with a much lower density than that of the pure drug. The shape of the agglomerates indicated the formation of the agglomerates in a sequential manner, starting from the core and finishing at the periphery. In literature it was reported that
A

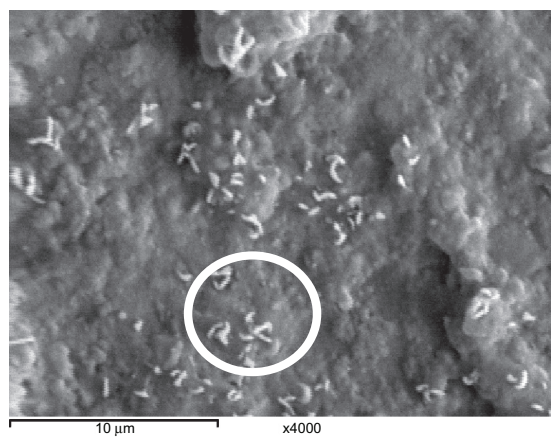

C

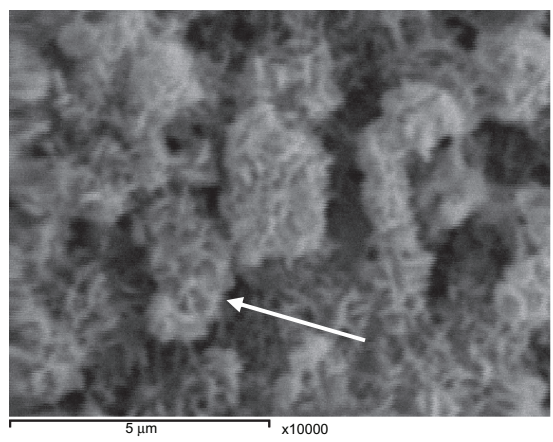

E

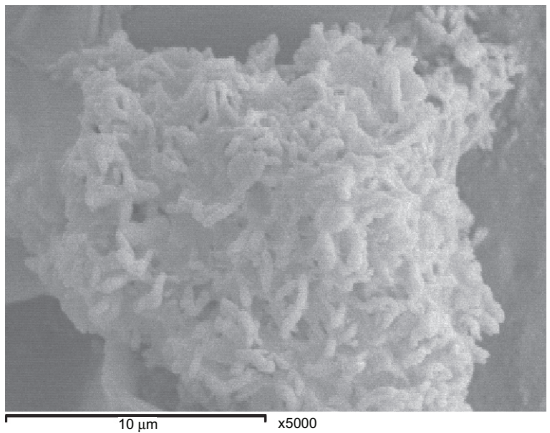

B

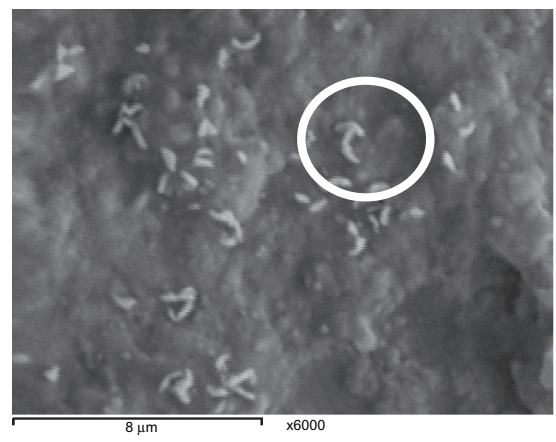

D

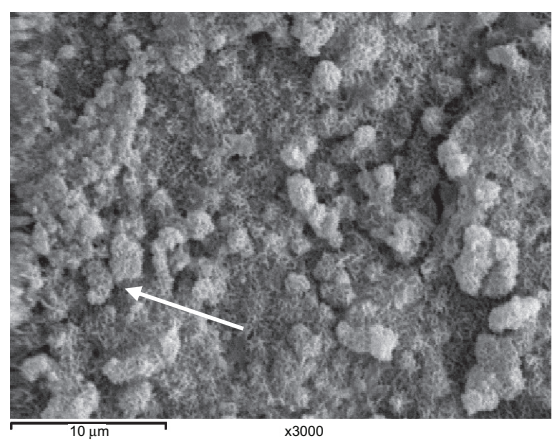

$\mathbf{F}$

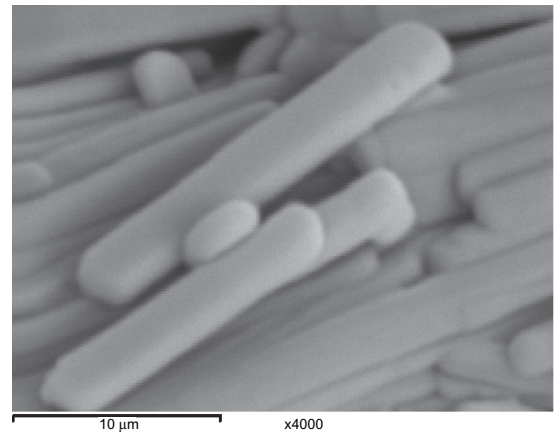

Figure I Nanoparticles (A), close up of theophylline nanoparticles (B), theophylline controlled agglomerates (C), close up of theophylline controlled agglomerates (D), aggregation of theophylline nanoparticles upon using high concentration of $\mathrm{NaCl}(\mathbf{E})$, and theophylline powder without processing (F). Note the circles that showing the mechanism of self-assembly of nanorods on a copper grid. The arrows show fluffy spherical nanorods of the controlled agglomerates. 
Table 2 The differences in zeta potential between nanoparticles and agglomerates at different $\mathrm{pH}$ ranges upon addition of diluted $\mathrm{NaCl}\left(0.5 \mathrm{~mL}, 10^{-3} \mathrm{M}\right)$ solution $(\mathrm{n}=3)$

\begin{tabular}{lll}
\hline pH value & \multicolumn{2}{l}{ Zeta potential $(\mathbf{m V})$} \\
\cline { 2 - 3 } & Nanoparticles & Agglomerates \\
\hline 3 & $-7.7 \pm 0.5$ & $-11.1 \pm 1.2$ \\
5.5 & $-37.9 \pm 2$ & $-24.9 \pm 2.1$ \\
7.4 & $-39.5 \pm 0.7$ & $-28.9 \pm 0.7$ \\
\hline
\end{tabular}

the particles agglomerate spontaneously and it was thought that they grouped together without order during the agglomeration steps. ${ }^{29}$ Controlled agglomeration was achieved through the addition of a very diluted concentration of $\mathrm{NaCl}$ $\left(0.5 \mathrm{~mL}, 10^{-3} \mathrm{M}\right)$, as shown in Figures $1 \mathrm{C}$ and $1 \mathrm{D}$, whereas aggregation was achieved by the addition of a 0.5 to $1 \mathrm{~mL}$ $(0.1 \mathrm{M})$ concentration of $\mathrm{NaCl}$, as shown in Figures 1E and $1 \mathrm{~F}$. The mean diameter of the agglomerate prepared using the diluted $\mathrm{NaCl}$ solution was of an average respirable size $(1-5 \mu \mathrm{m})$, with a median particle size of $2.47 \mu \mathrm{m}$ when stearic acid $(10 \% \mathrm{w} / \mathrm{w})$ was used. Less defined agglomerates were formed when a concentration of stearic acid lower than $10 \% \mathrm{w} / \mathrm{w}$ was used (Table 1 ).

The surface characteristics of the nanoparticles were subjected to a thorough study at different $\mathrm{NaCl}$ concentrations. Table 2 shows the differences in zeta potential values between nanoparticles and agglomerates at different $\mathrm{pH}$ ranges upon the addition of diluted $\mathrm{NaCl}$ solution $(0.5 \mathrm{~mL}$, $\left.10^{-3} \mathrm{M}\right)$. At physiological $\mathrm{pH}$, the agglomerated samples acquired a negative charge but to a lesser extent than that of the nanoparticles. The presence of these negative charges on the surface of the agglomerates kept the agglomerates in a definite shape (spheroidal agglomerates) when kept under dry conditions (Figures 1C and 1D) or when dissolved in water, as given by the photon correlation spectroscopy data (Table 1). The negative value of the zeta potential of the nanosuspensions reached $-39.3 \mathrm{mV}$ in the presence of $10 \%$ stearic acid, whereas it decreased to $-28.9 \mathrm{mV}$ upon agglomeration. These values provided colloidal stability for both the nanoparticles and the agglomerates. Both of these values are far from the aggregation threshold defined by Riddick. It was reported that a zeta potential value of nanoparticles of more than $-30 \mathrm{mV}$ indicates electrostatic repulsion among particles and is enough for good stability. ${ }^{58}$ A zeta potential range of -20 to $-11 \mathrm{mV}$ represents the threshold of aggregation as defined by Riddick. ${ }^{58}$ Therefore, complete neutralization of the stearic acid using $\mathrm{NaCl}(0.5-1.0 \mathrm{~mL}, 0.1 \mathrm{M})$ was found to produce big agglomerates that formed nuclei for bigger aggregates over time (Figure 1E). At low pH levels, the nanoparticles and the agglomerates carried fewer negative charges than they carried at physiological $\mathrm{pH}$. This may have been due to the lower degree of ionization of stearic acid at lower $\mathrm{pH}$ levels. This theory supports our assumption of stearic acid being the only provider of negative charges at the surface of the nanosuspension.

The percentage of the powders recovered differed markedly between the nanoparticles and agglomerates (Table 1). This phenomenon can be elucidated in light of the flowability characteristics, because nanoparticles with poor flowability usually show a low recovery because of difficulties and losses when transferring them from the vessels. ${ }^{29}$ The flowability parameters for the sample containing stearic acid $(10 \% \mathrm{w} / \mathrm{w})$ are summarized in Table 3 . The nanoparticles showed poorer flowability than the agglomerated particles, as predicted from both Carr's index and the Hausner ratio. This poor flowability of the nanoparticles may equate to the tendency of the nanoparticles to adhere to each other by increasing the particle-particle forces. ${ }^{59}$ The angle of repose shows that the nanoparticles had the poorest flow among all of the studied series, which is congruent with the other flow characteristics.

The theophylline agglomerate showed poor flowability as well, but to a lesser extent than that of the nanoparticles. This may be because the agglomerates had a mean particle size in the micro range, so they showed a lower tendency to reduce their surface area by forming bigger aggregates. The increase in the size of aerosol particles results in a lower surface area of particle-particle contact in a dry powder and a lower tendency for further aggregation, as reported by Edwards et al. ${ }^{28,60}$ This prevention of further aggregation means that less energy is necessary to aerosolize the agglomerates and hence results in an easier flow to the lungs. The densities of the theophylline powder, nano-

Table 3 Flowability parameters of theophylline powder, theophylline nanoparticles, and nanorose agglomerates

\begin{tabular}{llllll}
\hline Sample & $\begin{array}{l}\text { Bulk density } \\
\left(\mathbf{g m} / \mathbf{c m}^{3}\right)\end{array}$ & $\begin{array}{l}\text { Tapped density } \\
\left(\mathbf{g m} / \mathbf{c m}^{3}\right)\end{array}$ & $\begin{array}{l}\text { Carr's } \\
\text { index }\end{array}$ & $\begin{array}{l}\text { Hausner } \\
\text { ratio }\end{array}$ & $\begin{array}{l}\text { Angle of } \\
\text { repose }\left({ }^{\circ} \mathbf{C}\right)\end{array}$ \\
\hline Powder & $0.80 \pm 0.3$ & $1.40 \pm 0.2$ & $33 \pm 2$ & 1.5 & $65 \pm 2$ \\
Nanoparticles & $0.20 \pm 0.02$ & $0.29 \pm 0.01$ & $31 \pm 6$ & 1.45 & $80 \pm 1$ \\
Agglomerate & $0.04 \pm 0.01$ & $0.05 \pm 0.03$ & $25 \pm 2$ & 1.25 & $70 \pm 2$ \\
\hline
\end{tabular}




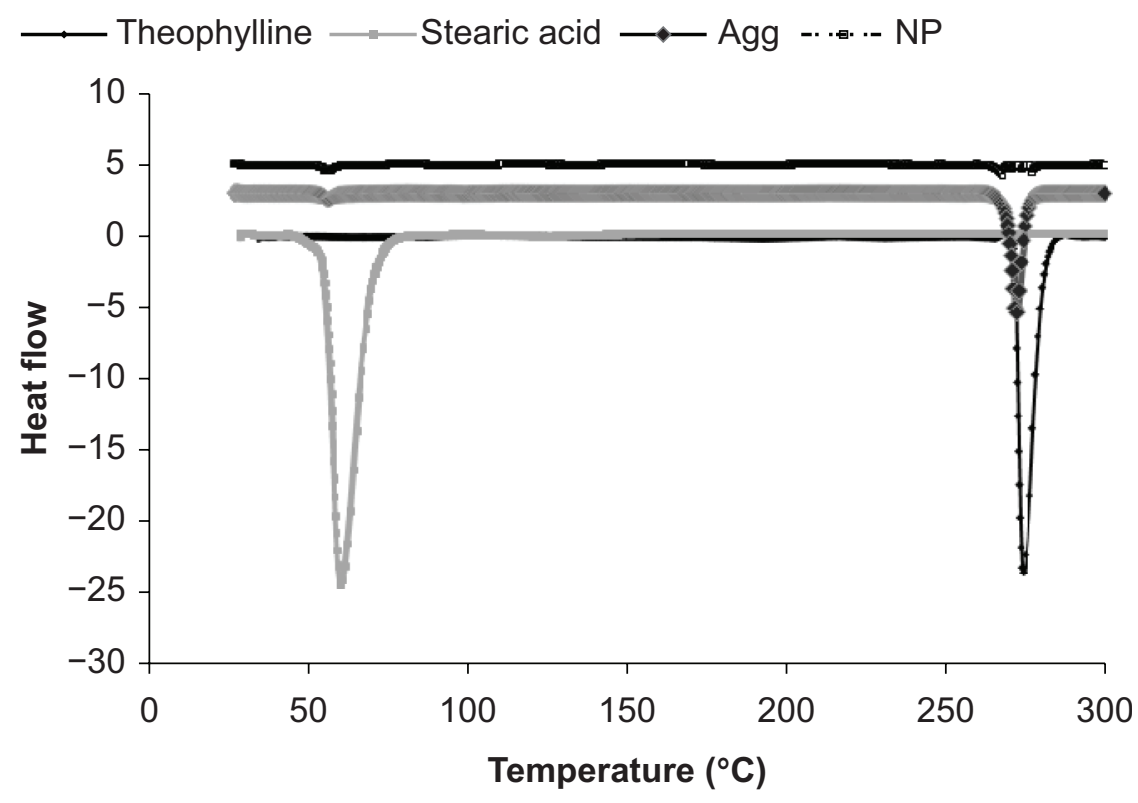

Figure 2 Differential scanning calorimetry thermograms for stearic acid, theophylline, theophylline nanoparticles, and theophylline agglomerates.

particles, and the agglomerates are in agreement with the powder structure seen in the electromicrographs in Figure 1, which show the formation of less dense nanoagglomerates of theophylline, which differ dramatically from the dense theophylline powder.

Differential scanning calorimetry thermographs were used to investigate the presence of chemical interactions between theophylline and stearic acid, in addition to monitoring changes in the crystalline state of the theophylline powder, nanoparticles, and agglomerates (Figure 2 and Table 4). Both theophylline and stearic acid exhibited sharp endothermic peaks when they underwent a melting phenomenon upon heating (Figure 2). The results showed a lack of interaction between the drug and stearic acid, which suggested the formation of a physical mixture in the case of the nanosuspension. It was also found that the enthalpy of the nanoparticles was lower than that of the pure drug, which may be attributed to the presence of a small amount of stearic acid surrounding the progesterone without invading it. However, there was no clear evidence to support this theory. The results showed an absence of a significant shift in the endothermic peak of theophylline in all of the samples (the peak shifted from $274^{\circ} \mathrm{C}$ in the theophylline powder to be $273^{\circ} \mathrm{C}$ in the case of the theophylline nanoparticles and to be $273.39^{\circ} \mathrm{C}$ in the case of the agglomerates), which is an indication of the lack of significant changes in the crystalline state of theophylline in all samples, and hence it is an indication of the presence of stearic acid on the surface but not within the theophylline molecules. The nanoparticles and the agglomerates showed lower peak areas on a per mass basis in contrast with the raw drug. It can be seen that the area of the peaks was reduced for the nanoparticles and, to a lesser extent, the agglomerates, which might be due to the higher surface area of both the nanoparticles and agglomerates in comparison with the theophylline. The results of the differential scanning calorimetry thermographs are summarized in Table 4 and Figure 2.

The in vitro dissolution profile of the nanoparticles, agglomerates, and theophylline powder (Figure 3) showed rapid release of the nanoparticles and the agglomerates in comparison with the theophylline powder. About $80 \%-90 \%$ of the nanoparticles were released throughout the duration of the experiment (eight hours). This rapid drug release was correlated with the particle size and increasing surface area of the nanoparticles. Therefore, small nanoparticles underwent a more rapid dissolution than both the agglomerate and the

Table 4 Differential scanning calorimetry peak integrations for theophylline powder, stearic acid powder, theophylline nanoparticles, and theophylline agglomerates in the lyophilized form

\begin{tabular}{lll}
\hline Sample & Peak location $\left({ }^{\circ} \mathbf{C}\right)$ & Enthalpy $(\mathbf{J} / \mathbf{g})$ \\
\hline $\begin{array}{l}\text { Theophylline } \\
\text { Stearic }\end{array}$ & 274.0 & 188 \\
$\begin{array}{l}\text { Nanosuspension } \\
\quad \text { Theophylline peak }\end{array}$ & 60.0 & 387 \\
$\quad$ & 272.9 & \\
$\quad$ Stearic peak & 55.6 & 53.08 \\
$\begin{array}{l}\text { Theophylline agglomerate } \\
\quad \text { Theophylline peak }\end{array}$ & 273.39 & 2.83 \\
$\quad$ Stearic peak & 70.01 & 118 \\
\hline
\end{tabular}




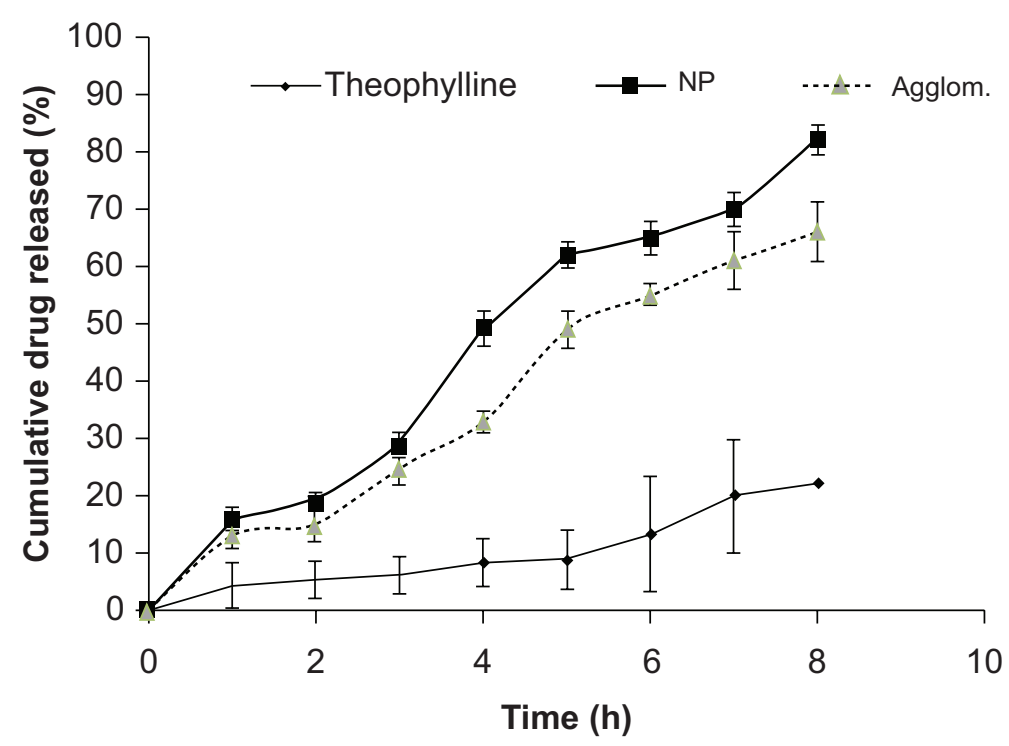

Figure 3 Cumulative drug released against time for the theophylline powder, theophylline nanoparticles, and theophylline agglomerates $(n=3 \pm$ standard deviation).

raw theophylline powder. About $69 \%$ of the agglomerate dissolved at the time of the experiment, and its dissolution profile overlaps with that of the nanoparticles at certain points. The difference was found to be significant at $P<0.05$ and the release kinetics were found to obey first-order kinetics with $r^{2}>0.96$. This may indicate the presence of more than one type of release kinetics controlling the release, which may have occurred due to the adsorption of fine molecules on the outer interphase of the nanosuspension. These small molecules might have dissolved readily and therefore interfered with the order of the release kinetics. This experiment indicates that the efficiency of both nanoparticles and the agglomerate in enhancing the release of the drug was higher than that of the raw theophylline powder alone. Therefore, both the agglomerate and nanosuspension might be dissolved rapidly in vivo.

The results of the aerodynamic characterization are shown in Table 5. The nanoparticles and the agglomerates resulted in significantly smaller mass median aerodynamic diameter $(P<0.05)$ and higher fine particle dose $(P<0.01)$, fine particle fraction $(P<0.01)$, and TED $(P<0.01)$ than the pure powder. There were no significant differences between the nanoparticles and the agglomerates. However, the agglomerates had a higher emitted dose and a higher fine particle dose and a lower mass median aerodynamic diameter than the nanoparticles. This might be due to the small number of determinations made for each system $(\mathrm{n}=5)$. This number was recommended by the compendial methods. $^{34-36}$

These findings are consistent with those reported previously in the literature. ${ }^{29}$ The aerodynamic characterization showed no significant differences between the agglomerate and the nanoparticles in all aspects. However, they both resulted in better aerodynamic characteristics than the pure powder. Therefore, the use of theophylline in the form of agglomerate or nanoparticle aerosols may result in better lung deposition than the use of the pure powder. However, a significant difference between the agglomerates and the nanoparticles might be recognized upon increasing the number of determinations, which would suggest that a future clinical bioequivalence test would be needed to consolidate this finding.

Table 5 The aerodynamic characteristics of theophylline, theophylline nanoparticles, and theophylline agglomerates

\begin{tabular}{lccc}
\hline Particles & Theophylline & Nanoparticles & Agglomerates \\
\hline Total emitted dose $(\mu \mathrm{g})$ & $59.9 \pm 8.5$ & $70.6 \pm 6.7$ & $72.3 \pm 7.5$ \\
Total emitted dose $(\%$ of nominal dose) & $75.5 \pm 11.4$ & $88.3 \pm 9.4$ & $90.4 \pm 10.3$ \\
Fine particle dose $(\mu \mathrm{g})$ & $33.3 \pm 12.2$ & $55.4 \pm 7.8$ & $57.4 \pm 6.7$ \\
Fine particle fraction $(\%$ of emitted dose) & $55.6 \pm 6.4$ & $81.9 \pm 4.3$ & $79.4 \pm 4.6$ \\
Mass median aerodynamic diameter $(\mu \mathrm{m})$ & $4.4 \pm 1.2$ & $2.5 \pm 1.1$ & $2.3 \pm 0.9$ \\
Geometric standard deviation & $2.2 \pm 0.5$ & $1.6 \pm 0.4$ & $1.4 \pm 0.3$ \\
\hline
\end{tabular}




\section{Acknowledgments}

The authors gratefully acknowledge Dr Mohammed AbdelGelil, AlArabia Medical Corporation, Egypt, who made available his support for the photon correlation spectroscopy measurements. MAS acknowledges the US Egypt Science and Technology. Joint funding through grant MA7-001-002 for partial support for this research.

\section{Disclosure}

The authors report no conflicts of interest in this work.

\section{References}

1. Geller D. Comparing clinical features of the nebulizer, metereddose inhaler, and dry powder inhaler. Respir Care. 2005;50(10): 1313-1321.

2. Rau J. The inhalation of drugs: Advantages and problems. Respir Care. 2005;50(3):367-382.

3. Pauwels R, Lofdahl C, Postma D, et al. Effect of inhaled formoterol and budesonide on exacerbations of asthma. N Engl J Med. 1997; 337(20):1405-1411.

4. Telko M, Hickey A. Dry powder inhaler formulation. Respir Care. 2005;50(9):1209-1227.

5. Taburet A, Schmit B. Pharmacokinetic optimisation of asthma treatment. Clin Pharmacokinet. 1994;26(5):396-418.

6. Markham A, Faulds D. Theophylline: A review of its potential steroid sparing effects in asthma. Drugs. 1998;56(6):1081-1091.

7. Mokra D, Drgova A, Mokry J, et al. Combination of budesonide and aminophylline diminished acute lung injury in animal model of meconium aspiration syndrome. J Physiol Pharmacol. 2008;59 Suppl 6: 461-471.

8. Barnes PJ, Peter JB, Ian WR, Neil CT. Theophylline. In: Barnes PJ, Rodger IW, Thomson NC, editors. Asthma: Basic Mechanisms and Clinical Management. 3rd ed. London: Academic Press; 1998.

9. Shen DD, Fixley M, Azarnoff DL. Theophylline bioavailability following chronic dosing of an elixir and two solid dosage forms. J Pharm Sci. 1978;67(7):916-919.

10. Koizumi S, Saito K, Murashima Y, Kawakami Y. Theophyllineinduced changes in mouse electroencephalograms. Brain Dev. 2010; 32(10):818-820.

11. Nadai M, Kato M, Yasui K, et al. Lack of effect of aciclovir on metabolism of theophylline and expression of hepatic cytochrome P450 1A2 in rats. Biol Pharm Bull. 2007;30(3):562-568.

12. Yang KH, Lee JH, Lee MG. Effects of CYP inducers and inhibitors on the pharmacokinetics of intravenous theophylline in rats: Involvement of CYP1A1/2 in the formation of 1,3-DMU. J Pharm Pharmacol. 2008;60(1):45-53.

13. Choi HD, Kang HE, Chung HJ, Bae SK, Shin KN, Lee MG. Effects of water deprivation on the pharmacokinetics of theophylline and one of its metabolites, 1,3-dimethyluric acid, after intravenous and oral administration of aminophylline to rats. Biopharm Drug Dispos. 2007;28(8): 445-454.

14. Hendeles L, Weinberger M, Johnson G. Monitoring serum theophylline levels. Clin Pharmacokinet. 1978;3(4):294-312.

15. Barnes PJ. Theophylline for COPD. Thorax. 2006;61(9):742-744.

16. Jacobs M, Senior R, Kessler G. Clinical experience with theophylline: Relationships between dosage, serum concentration, and toxicity. JAMA. 1976;235(18):1983-1986.

17. Hendeles L, Iafrate RP, Weinberger M. A clinical and pharmacokinetic basis for the selection and use of slow release theophylline products. Clin Pharmacokinet. 1984;9(2):95-135.

18. Owen J, Nakatsu K. Spectrophotometry of theophylline-7-acetic acid and theophylline. Clin Chem. 1978;24(2):367-368.
19. Benita S, Donbrow M. Release kinetics of sparingly soluble drugs from ethyl cellulose-walled microcapsules: Theophylline microcapsules. J Pharm Pharmacol. 1982;34(2):77-82.

20. Schulz HU, Steinijans VW, Gabel H. Differences in steady-state plasma levels between aminophylline and theophylline sustained-release micropellets after repeated circadian dosing. Int J Clin Pharmacol Ther Toxicol. 1984;22(11):621-625.

21. Hart S. Should aminophylline be abandoned in the treatment of acute asthma in adults? QJM. 2000;93(11):761-765.

22. Clausen T. Hormonal and pharmacological modification of plasma potassium homeostasis. Fundam Clin Pharmacol. 2010;24(5):595-605.

23. Zacarias EC, Castro AA, Cendon S. Effect of theophylline associated with short-acting or long-acting inhaled beta2-agonists in patients with stable chronic obstructive pulmonary disease: A systematic review. J Bras Pneumol. 2007;33(2):152-160. Spanish.

24. Ellis E, Koysooko R, Levy G. Pharmacokinetics of theophylline in children with asthma. Pediatrics. 1976;58(4):542-547.

25. Braat M, Jonkers R, Bel E, van Boxtel C. Quantification of theophyllineinduced eosinopenia and hypokalaemia in healthy volunteers. Clin Pharmacokinet. 1992;22(3):231-237.

26. Marriott C, MacRitchie HB, Zeng XM, Martin GP. Development of a laser diffraction method for the determination of the particle size of aerosolised powder formulations. Int J Pharm. 2006;326(1-2):39-49.

27. Zeng XM, MacRitchie HB, Marriott C, Martin GP. Correlation between inertial impaction and laser diffraction sizing data for aerosolized carrierbased dry powder formulations. Pharm Res. 2006;23(9):2200-2209.

28. Edwards D, Ben-Jebria A, Langer R. Recent advances in pulmonary drug delivery using large, porous inhaled particles. J Appl Physiol. 1998;85(2):379-385.

29. Plumley C, Gorman E, El-Gendy N, Bybee C, Munson E, Berkland C. Nifedipine nanoparticle agglomeration as a dry powder aerosol formulation strategy. Int J Pharm. 2009;369(1-2):136-143.

30. Zhao H, Le Y, Liu H, et al. Preparation of microsized spherical aggregates of ultrafine ciprofloxacin particles for dry powder inhalation (DPI). Powder Technol. 2009;194(1-2):81-86.

31. Sweeney L, Wang Z, Loebenberg R, Wong J, Lange C, Finlay W. Spray-freeze-dried liposomal ciprofloxacin powder for inhaled aerosol drug delivery. Int J Pharm. 2005;305(1-2):180-185.

32. Chougule M, Padhi B, Misra A. Nano-liposomal dry powder inhaler of tacrolimus: Preparation, characterization, and pulmonary pharmacokinetics. Int J Nanomedicine. 2007;2(4):675-688.

33. Morice A, Peterson S, Beckman O, Osmanliev D. Therapeutic comparison of a new budesonide/formoterol pMDI with budesonide pMDI and budesonide/formoterol DPI in asthma. Int J Clin Pract. 2007; 61(11):1874-1883.

34. European Pharmacopoeia. 2.9.18. Preparations for inhalation: Aerodynamic assessment of fine particles. Strasbourg, France: Council of Europe; 2002.

35. British Pharmacopoeia. Preparations for inhalation. Aerodynamic assessment of fine particles-fine particle dose and particle size distribution ( $\mathrm{Ph}$. Eur. method 2.9.18). London: British Pharmacopoeia; 2005.

36. United States Pharmacopeia. Aerosols, nasal sprays, metered dose inhalers and dry powder inhalers. United States Pharmacopeia and National Formulary; 2005.

37. Atia NN, York P, Clark BJ. Development and validation of a rapid and efficient method for simultaneous determination of methylxanthines and their metabolites in urine using monolithic HPLC columns. J Sep Sci. 2009;32(7):931-938.

38. Copley. Copley Scientific Catalogue. Available from: http:/www. copleyscientific.co.uk/new/inhaler\%20brochure\%202006\%20(hi\%20 res).pdf. Accessed December 16, 2006.

39. Van Oort M. In vitro testing of dry powder inhalers. Aerosol Sci Technol. 1995;22(4):364-373.

40. Bhavane R, Karathanasis E, Annapragada AV. Agglomerated vesicle technology: A new class of particles for controlled and modulated pulmonary drug delivery. J Control Release. 2003;93(1):15-28. 
41. Bhavane R, Karathanasis E, Annapragada AV. Triggered release of ciprofloxacin from nanostructured agglomerated vesicles. Int J Nanomedicine. 2007;2(3):407-418.

42. Bailey M, Gorman E, Munson E, Berkland C. Pure insulin nanoparticle agglomerates for pulmonary delivery. Langmuir. 2008;24(23): 13614-13620

43. Puechagut H, Bianchotti J, Chiale C. Preparation of norfloxacin spherical agglomerates using the ammonia diffusion system. J Pharm Sci. 1998;87(4):519-523.

44. Bailey M, Berkland C. Nanoparticle formulations in pulmonary drug delivery. Med Res Rev. 2009;29(1):196-212.

45. Matteucci M, Hotze M, Johnston K, Williams R IIIrd. Drug nanoparticles by antisolvent precipitation: Mixing energy versus surfactant stabilization. Langmuir. 2006;22(21):8951-8959.

46. Rasenack N, Steckel H, Müller B. Micronization of anti inflammatory drugs for pulmonary delivery by a controlled crystallization process. J Pharm Sci. 2003;92(1):35-44.

47. Mizoe T, Ozeki T, Okada H. Application of a four-fluid nozzle spray drier to prepare inhalable rifampicin-containing mannitol microparticles. AAPS PharmSciTech. 2008;9(3):755-761.

48. Ozeki T, Beppu S, Mizoe T, Takashima Y, Yuasa H, Okada H. Preparation of two-drug composite microparticles to improve the dissolution of insoluble drug in water for use with a 4-fluid nozzle spray drier. J Control Release. 2005;107(3):387-394.

49. Mizoe T, Ozeki T, Okada H. Preparation of drug nanoparticle-containing microparticles using a 4-fluid nozzle spray drier for oral, pulmonary, and injection dosage forms. J Control Release. 2007;122(1):10-15.

50. Salem H. Sustained-release progesterone nanosuspension following intramuscular injection in ovariectomized rats. Int $J$ Nanomedicine. 2010;5:943-954.

51. Shi L, Plumley C, Berkland C. Biodegradable nanoparticle flocculates for dry powder aerosol formulation. Langmuir. 2007;23(22): 10897-10901.
52. Chow A, Tong H, Chattopadhyay P, Shekunov B. Particle engineering for pulmonary drug delivery. Pharm Res. 2007;24(3):411-437.

53. Patil G, Matthews R, Cornwell D. Effect of ionization and cation selectivity on the expansion of stearic acid monolayers. J Lipid Res. 1972;13(5):574-579.

54. Patil G, Dorman N, Cornwell D. Effects of ionization and counterion binding on the surface areas of phosphatidic acids in monolayers. J Lipid Res. 1979;20(5):663-668.

55. Kumon M, Machida S, Suzuki M, Kusai A, Yonemochi E, Terada K. Application and mechanism of inhalation profile improvement of DPI formulations by mechanofusion with magnesium stearate. Chem Pharm Bull. 2008;56(5):617-625.

56. Nokhodchi A, Okwudarue ON, Valizadeh H, Momin MN. Cogrinding as a tool to produce sustained release behavior for theophylline particles containing magnesium stearate. AAPS PharmSciTech. 2009; 10(4):1243-1251.

57. Fults K, Miller I, Hickey A. Effect of particle morphology on emitted dose of fatty acid-treated disodium cromoglycate powder aerosols. Pharm Dev Technol. 1997;2(1):67-79.

58. Riddick T. Control of colloid stability through zeta potential: With a closing chapter on its relationship to cardiovascular disease, 1968. Available from: http://www.hbci.com/ wenonah/riddick/chap22.htm. Accessed on January 11, 2011.

59. Molimard M, Raherison C, Lignot S, Depont F, Abouelfath A, Moore N. Assessment of handling of inhaler devices in real life: An observational study in 3811 patients in primary care. J Aerosol Med. 2003;16(3): 249-254.

60. Vanbever R, Mintzes JD, Wang J, et al. Formulation and physical characterization of large porous particles for inhalation. Pharm Res. 1999;16(11):1735-1742.
International Journal of Nanomedicine

\section{Publish your work in this journal}

The International Journal of Nanomedicine is an international, peerreviewed journal focusing on the application of nanotechnology in diagnostics, therapeutics, and drug delivery systems throughout the biomedical field. This journal is indexed on PubMed Central, MedLine, CAS, SciSearch $\AA$, Current Contents ${ }^{\circledR} /$ Clinical Medicine,

\section{Dovepress}

Journal Citation Reports/Science Edition, EMBase, Scopus and the Elsevier Bibliographic databases. The manuscript management system is completely online and includes a very quick and fair peer-review system, which is all easy to use. Visit http://www.dovepress.com/ testimonials.php to read real quotes from published authors. 